\title{
Establishing Patient Loyalty by Investigating Its Relationship with Relationship Quality, Alternative Attractiveness, and Patient Gratitude in Hospitals
}

\author{
Pao-Chun Hsieh ${ }^{1}$, Yii-Ching Lee ${ }^{2,3}, 4$, Hsin-Hung Wu ${ }^{5}$, 6, Chih-Hsuan Huang7 , Li Li ${ }^{*}$ \\ 1 Department of Obstetrics and Gynecology, Cheng Ching General Hospital-Chung Kang Branch, Taichung \\ City, Taiwan. \\ 2 School of Health Policy and Management, Chung Shan Medical University, Taichung, Taiwan. \\ 3 Department of Health Business Administration, Hung Kuang University, Taichung City, Taiwan. \\ ${ }^{4}$ Shanghai Changtai Healthcare Management Co., Ltd., Shanghai, China. \\ 5 Department of Business Administration, National Changhua University of Education, Changhua City, \\ Taiwan. \\ 6 Department of M-Commerce and Multimedia Applications, Asia University, Taichung City, Taiwan. \\ ${ }^{7}$ School of Business Administration, Hubei University of Economics, Wuhan City, China. \\ ${ }^{8}$ School of Management, Wuhan Institute of Bioengineering, Wuhan City, China. \\ * Corresponding author. Tel.: +86 27 89648757; email: Lisat23@163.com \\ Manuscript submitted March 19, 2017; accepted July 25, 2017. \\ doi: 10.17706/ijeeee.2018.8.1.58-65
}

\begin{abstract}
Recently hospitals are facing several challenges in a competitive medical market, how to enhance physician-patient relationship becomes an important concern for hospitals to better improve medical quality and patient loyalty. However, the enhancement of patient loyalty through a better physician-patient relationship is still ambiguous in healthcare field. The purpose of this study aims to examine the physician-patient interaction, and to further investigate the relationships among relationship quality, patient gratitude, alternative attractiveness, and patient loyalty. The findings revealed that both satisfaction and commitment had positive effects on patient loyalty whereas trust had no significant impact on patient loyalty. Additionally, gratitude demonstrated a significant effect on patient loyalty. In addition, patient loyalty was found to have no significant impact on patient loyalty. Healthcare management should pay more attention to relationship-oriented elements (such as relationship quality and gratitude) in order to provide a better physician-patient relationship in medical service industries.
\end{abstract}

Key words: Alternative attractiveness, patient gratitude, patient loyalty, relationship quality.

\section{Introduction}

According to the annual report of the National Health Insurance Administration (NHIA), the National Health Insurance (NHI) system now covers $99.6 \%$ of Taiwan's population in 2016 [1]. Obstacles to medical care have been eliminated, and patients not only can freely choose hospitals but they also expect higher quality medical care [2]. In the past the interaction between physicians and patients was normally restricted to patients' compliance with physicians' instruction [3]. In fact, both physicians and patients need to engage in an interactive process because of the uncertainties and complex process of medical treatment. Various studies on relationship marketing have confirmed that a good relationship quality is based on a long-term relationship between patients and hospitals [4], [5], and this high-quality relationship is an 
essential component that leads to a sustainable development for hospitals in a competitive medical service industry [6]. However, empirical practices of healthcare organizations concerning the enhancement of patient loyalty through maintenance of good relationships with patients are still ambiguous [7]. For example, in the field of medical services, it is common that a patient through words or behavior expresses his or her gratitude to the medical staff due to their endeavor to rescue the patient's life and health. Few studies have clearly identified the connection between patient gratitude and patient loyalty. As hospitals seek to create a long-term relationship with the patient to in turn enhance performance in a complex and competitive medical market, it is therefore important to recognize the essential instrument for promoting patient loyalty. Following this introduction, the second section of this paper presents a review of the framework and relevant hypotheses. The third section then illustrates details of the methods used in the empirical study. Finally, the results are discussed.

\section{Framework and Hypothesis}

Relationship quality is developed from relationship marketing, and emphasizes on the establishment of long-term mutually beneficial relationships with customers [8]. While there are different conceptualizations of relationship quality, it consists mainly of the three aspects of satisfaction, trust and commitment [9]-[11]. Studies on healthcare services have suggested that satisfaction, trust, and commitment are important factors that influence patient loyalty [4], [5]. These three components of relationship quality represent the perceptions of evaluation in the relationship, which helps to build a better physician-patient relationship. However, a stronger physician-patient relationship can not only rely on the quality of relationship, there has been little discussion of other important factors affecting patient loyalty in the medical service industries, specifically, through a better physician-patient relationship.

The concept of gratitude has been widely discussed to enhance a long-term relationship between a customer and company in the marketing field [3]. Eggert et al. [12] proposed that a customer-oriented program provided by an enterprise would contribute to customer's loyalty intentions via customer gratitude. Customers feel they should maintain the relationship and express the thankfulness by returning loyalty [13]. In the field of medical services, it is still unclear whether patient gratitude will predict the relationship between physicians and patients. This study thus proposes that patient's gratitude could be a central stimulant for the interaction between the medical staff and patient, since patient's appreciation may have a positive impact on the likelihood of patient's returning to the hospital or promoting the hospital through word of mouth. In addition, the healthcare environment has been increasingly competitive, and establishing a patient-oriented service has become important for improving the medical service quality and rights of patients in the hospitals in order to achieve sustainable development. Vázquez-Carrasco \& Foxall [14] further pointed out that if the consumer perceives that an alternative exists in the market, then the higher the alternative attractiveness, the more appealing it is to the consumer to accept medical treatment in another hospital. Alternative attractiveness reflects a driving force that stimulates an individual to switch to other products or services, and has a positive correlation with the consumer's switching intention [15]. Thus, a hospital manager in the face of alternative competitors should enhance its existing commitment to the physician-patient relationship in order to survive in a competitive market.

Based on the discussions above, this study therefore aimed to investigate the potential factors that supplement the contribution of patient loyalty, as shown in Fig. 1. The hypotheses are proposed as follows:

$\mathrm{H}_{1}$ : A patient's perception of relationship quality will positively influence patient loyalty

$\mathrm{H}_{1-1}$ : A patient's satisfaction will positively influence patient loyalty

$\mathrm{H}_{1-2}$ : A patient's trust will positively influence patient loyalty

$\mathrm{H}_{1-3}$ : A patient's commitment will positively influence patient loyalty 
$\mathrm{H}_{2}$ : Alternative attractiveness will negatively influence patient loyalty $\mathrm{H}_{3}$ : Patient gratitude will positively influence patient loyalty

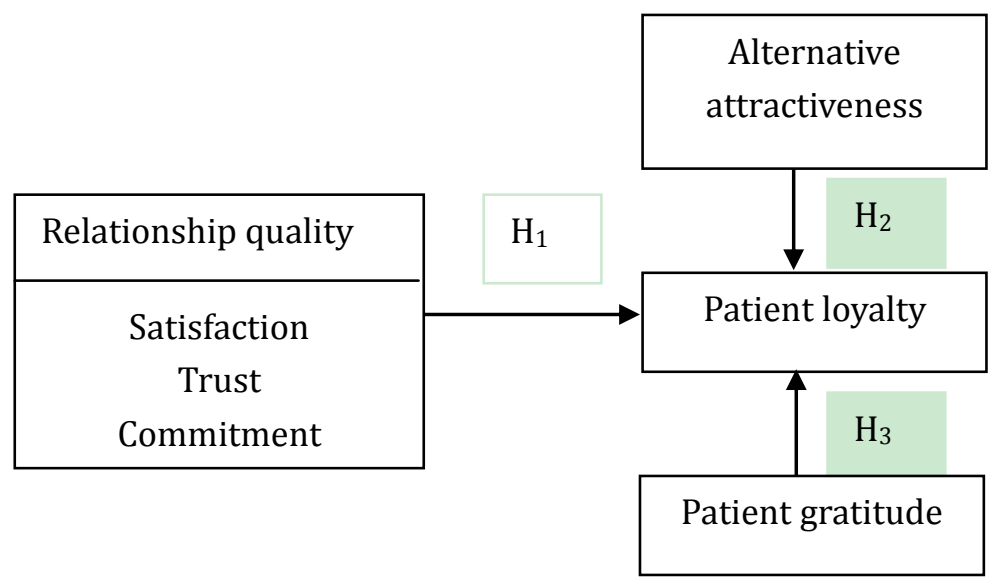

Fig. 1. Research framework.

\section{Methodology}

\subsection{Data Collection and Analysis}

Respondents who received medical treatment in any hospital in Taiwan during the year of 2015 were requested to respond to the survey. A total of 400 questionnaires were collected using convenience sampling, and 396 valid questionnaires were used for the analysis. After data screening, a confirmatory factor analysis (CFA) was performed using Amos 20.0 to verify the structure of constructs. Multiple regression analysis was sequentially employed using SPSS 20.0 to identify the relationships among the constructs.

\subsection{Measurement and Data Analysis}

As shown in Table 1, items from prior research were used as the basis of measurement. Relationship quality consists of satisfaction, trust and commitment. Eleven items were used to measure satisfaction; five items were used to measure trust; and six items were used to assess commitment. Alternative attractiveness was assessed using four items. Five items and six items were adapted to evaluate patient gratitude and patient loyalty, respectively. Five-point Likert scales anchored by 1 (strongly disagree) and 5 (strongly agree) were used throughout the questionnaire. Additionally, all questions in alternative attractiveness dimension are reversed questions such that each respondent's answer is adjusted.

Table 1. Measurement Items

\begin{tabular}{lll}
\hline \hline Construct & Item & Source \\
\hline Satisfaction & 11 & Moliner [16]; Hsieh \& Hiang [17]; Golicic \& Mentzer [18] \\
Trust & 5 & Moliner [16]; Hsieh \& Hiang [17]; Golicic \& Mentzer [18] \\
Commitment & 6 & Walter et al. [19]; Golicic \& Mentzer [18] \\
Alternative attractiveness & 4 & Jeng [20]; Jones et al. [21] \\
Patient gratitude & 5 & Lanham et al. [22]; Palmatier et al. [3] \\
Patient loyalty & 6 & Zeithaml et al. [23]; Ibáñez et al. [24] \\
\hline \hline
\end{tabular}




\section{Research Results}

\subsection{Sample Characteristics}

The sample profile demonstrated that majority of the respondents were female (64.4 percent), their age ranged from 31 to 50 years (53.8 percent), and they were educated up to the bachelor's level (52.3 percent). Around one-third of the respondents reported that they worked in the service industry. Over a half of the respondents reported that their monthly income was around TWD $\$ 16,000$ to TWD $\$ 48,000$. Fifty point eight percent of the respondents reported regional hospital is their first priority. Majority of the respondents received their treatments via outpatient service $(51.5 \%)$ and the frequencies of average treatment services were around one to three months (44.5 percent).

\subsection{Empirical Results}

This study first confirmed that each measure taps facets of the intended construct (convergent validity) and that the constructs are distinct from each other (discriminant validity) by using CFA [25](Gerbing \& Anderson, 1988). The CFA results indicated that the measurement model meet appropriate levels of goodness-of-fit statistics. For example, acceptable absolute fit indices $\left(\chi^{2} / \mathrm{df}=3.168, \mathrm{GFI}=0.77, \mathrm{RMR}=0.02\right.$, and RMSEA $=0.07$ ), incremental fit indices (TLI $=0.89$, CFI $=0.90$, and IFI $=0.90)$, and parsimonious fit indices $(\mathrm{PNFI}=0.80$ and PGFI $=0.67$ ) were demonstrated [26], [27]. Table 2 showed that all the Cronbach alpha coefficients range between 0.874 (alternative attractiveness) and 0.949 (trust) and thus exceed the suggested threshold of 0.70 [28]. Additionally, the CFA results revealed that the composite reliability (CR) of the scales exceed the recommended of 0.70 threshold as well as the average variance extracted (AVE) estimates were above 0.50, providing evidence of convergent validity [26], [27], [29]. Additionally, the highest mean score was observed for trust, while the lowest mean score was on alternative attractiveness.

Table 2. The Results of Mean, SD, Cronbach Alpha, CR, and AVE ( $n=396)$

\begin{tabular}{lccccc}
\hline \hline Construct & Mean & SD & $\alpha$ & CR & AVE \\
\hline Satisfaction & 3.925 & 0.5213 & 0.936 & 0.971 & 0.758 \\
Trust & 4.001 & 0.5676 & 0.949 & 0.979 & 0.906 \\
Commitment & 3.824 & 0.5744 & 0.910 & 0.955 & 0.780 \\
Alternative attractiveness & 2.670 & 0.6356 & 0.874 & 0.926 & 0.763 \\
Patient loyalty & 3.737 & 0.6360 & 0.918 & 0.956 & 0.766 \\
Patient gratitude & 3.937 & 0.5959 & 0.948 & 0.977 & 0.895 \\
\hline \hline
\end{tabular}

Note: SD: standard deviation; $\alpha$ : Cronbach alpha; CR: composite reliability; AVE: average variance extracted

As shown in Table 3, we conducted a Pearson's Correlation Analysis to realize the relationships among six constructs. The results of Pearson's Correlation Analysis demonstrated that satisfaction was highly significant to trust and commitment. Satisfaction, trust, and commitment were also significantly related to patient gratitude and patient loyalty, respectively. In addition, patient gratitude was positively related to patient loyalty. On the other words, most constructs had no relations with alternative attractiveness.

Table 3. The Results of Pearson's Correlation Analysis $(n=396)$

\begin{tabular}{lllllll}
\hline \hline Construct & 1 & 2 & 3 & 4 & 5 & 6 \\
\hline 1.Satisfaction & & & & & & \\
2.Trust & $0.758^{* *}$ & & & & \\
3.Commitment & $0.810^{* *}$ & $0.732^{* *}$ & & & \\
4.Alternative attractiveness & 0.052 & 0.091 & $0.122^{*}$ & & \\
5.Patient loyalty & $0.768^{* *}$ & $0.642^{* *}$ & $0.766^{* *}$ & 0.047 & \\
6.Patient gratitude & $0.781^{* *}$ & $0.712^{* *}$ & $0.697^{* *}$ & 0.051 & $0.747^{* *}$ \\
\hline \hline
\end{tabular}

Note: * $p<0.05$; $^{* *}: p<0.01$ 
The results of multiple regression analysis showed that satisfaction $(\beta=0.239, p=0.00)$ and commitment $\left(\beta=0.383, p=0.00\right.$ ) had a positive impact on patient loyalty, which supports $\mathrm{H}_{1-1}$ and $\mathrm{H}_{1-3}$, whereas trust $(\beta$ $=-0.055, p=0.245$ ) had no significant impact on patient loyalty; therefore, $\mathrm{H}_{1-2}$ was not supported. Alternative attractiveness $(\beta=-0.25, p=0.384$ ) was found to have no significant impact on patient loyalty. This supports $\mathrm{H}_{2}$. Patient gratitude $(\beta=0.334, p=0.00)$ had a significant and positive relationship with patient loyalty, providing support for $\mathrm{H}_{3}$.

\section{Discussion}

Establishing a close physician-patient relationship and providing good medical services have become keys to strengthen patient loyalty in a highly competitive medical service industry. The purpose of the current study was to investigate the predict power of relationship quality, patient gratitude, and alternative attractiveness on patient loyalty. The results of our study revealed that satisfaction and commitment were found to contribute to patient loyalty, which are consistent with previous studies that indicated that a solid loyalty could be stimulated by patients' perceived satisfaction in the hospital services and also by a supportive commitment from the hospital in the healthcare service industry [30], [31]. However, trust does not have a significant effect on patient loyalty. One possible explanation for this finding is that a good physician-patient relationship is more likely to be achieved by a result-oriented element during treatment process. It is easier to lose patient's loyalty without certain results (e.g. satisfied medical services or acceptable medical expenses) if the hospital just relies on the promotion of trustiness. Our study illustrated that confirmed that gratitude importantly drives a successful relationship between the physician and patient. Gratitude is a critical factor in enhancing patient loyalty. Hence, potentially relevant factors that influence patient gratitude should be further explored. Additionally, alternative attractiveness was found to have no significant impact on patient loyalty. One possible explanation for this finding is that the medical ecology is gradually mature in Taiwan. Generally speaking, medical resources and professional medical level of physicians are adequate for most hospitals. These attractiveness factors might be the main reasons to influence patients' healthcare choice. This study has its limitations. Our research framework was assessed in the healthcare context; therefore, whether this model could be generalized to other contexts requires further empirical investigation. The respondents were Taiwanese clients, but the results may not be generalizable to other populations.

\section{Acknowledgment}

This study were supported by Cheng Ching General Hospital in Taichung City, Taiwan with the grant number of CH10500188, and by Hubei University of Economics with the grant number of XJ16BS34.

\section{References}

[1] National Health Insurance Administration. (2016). National Health Insurance 2015-2016 Annual Report. Taipei, Taiwan.

[2] Lee, S. F., \& Hsieh S. R. (2009). Effects of the quality of healthcare and the physician-patient relationship on patient loyalty: An empirical study of the department of cardiac surgery. Journal of Healthcare Management, 10(3), 165-182.

[3] Palmatier, R. W., Jarvis, C. B., Bechkoff, J. R., \& Kardes, F. R. (2009). The role of customer gratitude in relationship marketing. Journal of Marketing, 73(5), 1-18.

[4] Huang, J. A., Lai, C. S., Hu, J. S., \& Weng, R. H. (2014). The impact of market orientation on patient loyalty: The mediation of relationship quality. Service Business, 8(4), 499-515.

[5] Chiang, H. S. (2014). The reaching and application of alternative medicine in medical education 
programs. Journal of Nursing, 61(6), 5-11.

[6] Chang, S. S., Chen, S. Y., \& Lan, Y. T. (2013). Service quality, trust, and patient satisfaction in interpersonal-based medical service encounters. BMC Health Services Research, 13, 22.

[7] Weng, R. H., Huang, C. Y., \& Chiu, P. S. (2008). The impact of relationship quality and relational benefit on customer loyalty in healthcare industry. Sun Yat-Sen Management Review, 16(3), 543-574.

[8] Crosby, L. A., Kenneth, R. E., \& Cowles, D. (1990). Relationship quality in services selling: An interpersonal influence perspective. Journal of Marketing, 54, 68-81.

[9] Ndubisi, N. O. (2014). Consumer mindfulness and marketing implications. Psychology of Marketing, 31(4), 237-250.

[10] Steward, M. D., Wu, Z., \& Hartley, J. L. (2010). Exploring supply managers' intrapreneurial ability and relationship quality. Journal of Business-to-Business Marketing, 17(2), 127-148.

[11] McDonnell, J., Beatson, A., \& Huang, C. H. (2011). Investigating relationships between relationship quality, customer loyalty and cooperation: An empirical study of convenience stores' franchise chain systems. Asia Pacific Journal of Marketing and Logistics, 23(3), 367-385.

[12] Eggert, A., Steinhoff, L., \& Garnefeld, I. (2015). Managing the bright and dark sides of status endowment in hierarchical loyalty programs. Journal of Service, 18(2), 210-228.

[13] Esmark, C. L., Nobel, S. M., \& Bell, J. E. (2016). Open versus selective customer loyalty programmes. European Journal of Marketing, 50(5/6), 770-795.

[14] Vázquez-Carrasco, R., \& Foxall, G. R. (2006). Positive vs. negative switching barriers: The influence of service consumers' need for variety. Journal of Consumer Behaviour, 5(4), 367-379.

[15] Lu, T., Tu, R., \& Jen, W. (2011). The role of service value and switching barriers in an integrated model of behavioural intentions. Total Quality Management \& Business Excellence, 22(10), 1071-1089.

[16] Moliner, M. A. (2009). Loyalty, perceived value and relationship quality in healthcare services. Journal of Service Management, 20(1), 76-97.

[17] Hsieh, Y. C., \& Hiang, S. T. (2004). A study of the impacts of service quality on relationship quality in search-experience-credence services. Total Quality Management and Business Excellence, 15(1), 43-58.

[18] Golicic, S. L., \& Mentzer, J. T. (2006). An empirical examination of relationship magnitude. Journal of Business Logistics, 27(1), 81-108.

[19] Walter, A., Muller, T. A., Helfert, G., \& Ritter, T. (2003). Functions of industrial supplier relationships and their impact on relationship quality. Industrial Marketing Management, 32(2), 159-169.

[20] Jeng, S. P. (2004). Customer loyalty in competitive markets: Alternative attractiveness, switching costs and satisfaction effects. Fu Jen Management Review, 11, 77-96.

[21] Jones, M. A., Mothersbaugh, D. L., \& Beatty, S. E. (2000). Switching barriers and repurchase intentions in services. Journal of retailing, 76(2), 259-274.

[22] Lanham, M. E., Rye, M. S., Rimsky, L. S., \& Weill, S. R. (2012). How gratitude relates to butnout and job satisfaction in mental health professionals. Journal of Mental Health Counseling, 34(4), 341-354.

[23] Zeithaml, V. A., Berry, L. L., \& Parasuraman, A. (1996). The behavioral consequences of service quality. The Journal of Marketing, 60(2), 31-46.

[24] Ibáñez, V. A., Hartmann, P., \& Calvo, P. Z. (2006) Antecedents of customer loyalty in residential energy markets: Service quality, satisfaction, trust and switching costs. Service Industries Journal, 26(6), 633-650.

[25] Gerbing, D. W., \& Anderson, J. C. (1988). An updated paradigm for scale development incorporating unidimensionality and its assessment. Journal of Marking Research, 25(2), 186-92.

[26] Hu, L. T., \& Bentler, P. M. (1999). Cutoff criteria for fit indexes in covariance structure analysis: Conventional criteria versus new alternatives. Structural Equation Modeling: A Multidisciplinary 
Journal, 6(1), 1-55.

[27] Bagozzi, R. P., \& Yi, Y. (1988). On the evaluation of structural equation models. Journal of the Academy of Marketing Science, 16(1), 74-94.

[28] Nunnally, J. C. (1978). Psychometric Theory (2 ed.). New York: McGraw-Hill.

[29] Fornell, C., \& Larcker, D.F. (1981). Evaluating structural equation models with unobservable variables and measurement error. Journal of Marketing Research, 18(1), 39-50.

[30] Platonova, E. A., Kennedy, K. N., \& Shewchuk, R. M. (2008). Understanding patient satisfaction, trust, and loyalty to primary care physicians. Medical Care Research and Review, 65(6), 696-712.

[31] Moreira, A. C., \& Silva, P. M. (2015). The trust-commitment challenge in service quality-loyalty relationships. International Journal of Health Care Quality Assurance, 28(3), 253-266.

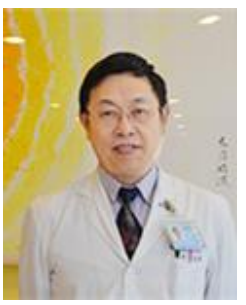

Hsieh Pao-Chun is the director in the Department of Obstetrics and Gynecology at Cheng Ching General Hospital, Chung Kang Branch in Taichung, Taiwan. Dr. Hsieh received his M.D. with Graduate Certificate in Department of Medicine from National Defense Medical Center, Taipei, Taiwan. His major expertise includes general gynecology, general obstetrics, high-level prenatal ultrasound diagnosis, laparoscopic surgery, women's cancer, urinary incontinence and genital tract surgery, high-risk pregnancy care and obstetrics. His main areas of research interests are in obstetrics and gynecology and medical quality.

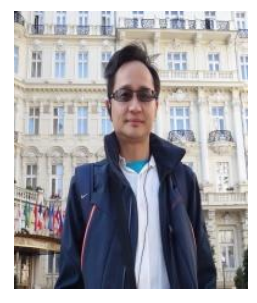

Yii-Ching Lee is the adjunct assistant professor at the Department of Hospitality Management in Hungkuang University, and at the School of Health Policy and Management in Chung Shan Medical University, the director in the Quality Management Center at Kushan Changtai Healthcare Management Co. Dr. Lee received his Ph.D. with Graduate Certificate in Graduate Institute of Business Administration from National Chung Cheng University, Chia-Yi, Taiwan in 2014. His major experience includes the Collaborative Director in the Department of Medical Quality Management and Director in the H.R. at Cheng Ching General Hospital-Chung Kang Branch and the administrator at the strategic planning division in Landseed Hospital. His main areas of research interests are in medical quality, patient safety, rational bond, rational marketing, and hospital management.

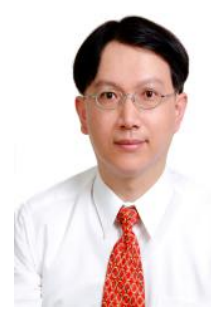

Hsin-Hung Wu is a university distinguished professor at National Changhua University of Education (NCUE), Changhua, Taiwan since August 2014. He is with the Department of Business Administration at NCUE since August 2004. In addition, he is an adjunct chair professor at Asia University, Taichung City, Taiwan since February 2017. He was elected as a fellow of International Economics Development and Research Center (IEDRC) in 2013. Dr. Wu received his Ph.D. degree in the Department of Industrial \& Systems Engineering and Engineering Management at University of Alabama in Huntsville, Huntsville, AL, USA in May 1998. His research interests include service quality, patient safety, decision analysis, data mining, and applied statistics. He has published more than 140 journal papers and 200 conference papers. In recent years, Dr. Wu has received several awards, i.e., Outstanding Young Industrial Engineer Award from the Chinese Institute of Industrial Engineers (Taiwan) in December 2008, Quality Award for Individuals from the Chinese Society for Quality (Taiwan) in November 2011, and Mr. Lu Feng Zhang Memorial Medal from the Chinese Management Association (Taiwan) in December 2012, Special Outstanding Talent Award by Ministry of Science and Technology since October 2010, and Outstanding Research Faculty Award three times from NCUE. 


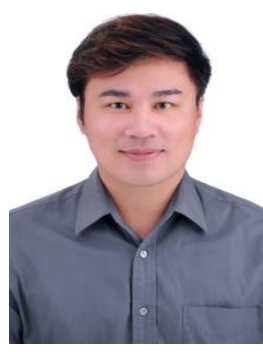

Chih-Hsuan Huang received his Ph.D. in consumer behavior from Queensland University of Technology, Brisbane, Australia in 2013. He is a lecturer in the School of Business Administration at Hubei University of Economics, Wuhan City, China.

He was elected as an International Economics Development Research Center (IEDRC) Fellow Member in Jan. 2016. He is a technical program committee for 2017 International Conference on Economic Development and Enterprise Innovation (EDEI) and 2017 International Conference on Financial Technology (ICFT). Moreover, he serves as Reviewer for INQUIRY: The Journal of Health Care Organization, Provision, and Financing (indexed in Social Science Citation Index). His research in these areas has appeared in a journal such as Asia Pacific Journal of Marketing and Logistics, International Journal of Health Care Quality Assurance, Journal of Management Research, Asia Journal of Business and Management, Journal of Computing and Information Science in Engineering, etc. His research interests include green consumer behavior, relationship marketing, sustainable management and patient safety.

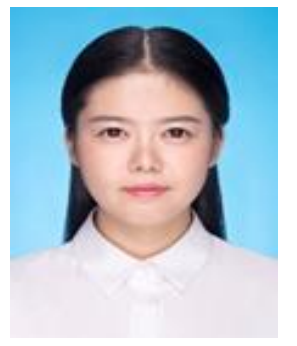

Li Li is a lecturer in the School of Management at Wuhan Institute of Bioengineering, Wuhan City, China. She earned her master degree from Hubei University of Economics in 2017. Her research areas include relationship marketing and stock incentive compensation, and patient safety culture. 